\title{
Necessary Skills for Success in Higher Learning
}

\begin{abstract}
The study focuses on identifying whether other factors, apart from academic qualification, are needed to ensure success in higher learning.
\end{abstract}

Keyword: Critical Thinking, Personality, Emotional Intelligence, Problem Solving Skills, Time Management Skills, Study Skills 